\title{
NARRATIVAS NA FORMAÇÃO COMUM DE PROFISSIONAIS DE SAÚDE
}

\author{
NARRATIVES IN THE COMMON TRAINING OF HEALTH PROFESSIONALS
}

NARRATIVAS EN LA FORMACIÓN COMÚN DE PROFESIONALES DE LA SALUD

\author{
Angela Aparecida Capozzolo ${ }^{1}$ \\ Sidnei José Casetto ${ }^{2}$ \\ Jaquelina Maria Imbrizi ${ }^{3}$ \\ Alexandre de Oliveira Henz ${ }^{4}$ \\ Roberto Tykanori Kinoshita ${ }^{5}$ \\ Maria de Fátima Ferreira Queiroz ${ }^{6}$
}

Resumo Este texto relata a experiência de formação comum que ocorre desde 2007 no campus Baixada Santista da Universidade Federal de São Paulo, no terceiro semestre de graduação, do eixo curricular trabalho em saúde. A experiência articula estudantes e docentes de diferentes áreas profissionais: educação física, fisioterapia, nutrição, psicologia e terapia ocupacional. São apresentadas as diretrizes e estratégias de organização do módulo 'Prática clínica integrada: análise de demandas e necessidades de saúde', que adota a produção de narrativas de histórias de vida e de questões de saúde de pessoas selecionadas por docentes em conjunto com as equipes da rede de serviços do município de Santos, São Paulo. As narrativas foram produzidas em encontros quinzenais dos estudantes com as pessoas acompanhadas em suas residências e de supervisões com os docentes. Realizou-se análise de conteúdo de 120 relatórios de conclusão do módulo elaborados pelos estudantes nos anos de 2007 e 2008 visando identificar efeitos dessa proposta de formação. A elaboração de narrativas favoreceu aos estudantes ampliar a capacidade de escuta e a percepção da complexidade do processo saúdedoença-cuidado, bem como de outros aspectos do que se tem denominado de 'clínica comum' às diversas profissões em saúde.

Palavras-chave trabalho em saúde; narrativa; prática clínica; formação interprofissional.

\begin{abstract}
This account reports on the experience of the common training that has been taking place since 2007 at the Baixada Santista campus of the Federal University of São Paulo (Southeast Brazil), in the third semester of the undergraduate course, under the health work axis of the curriculum. The experience includes students and professors from different professional areas, ranging from physical education, physical therapy, nutrition, psychology to occupational therapy. The account presents the guidelines and strategies for organizing the 'Integrated clinical practice: analysis of health needs and demands' module, which adopts the production of life history narratives and health issues of people selected by professors together with the teams of the service network from the municipality of Santos, state of São Paulo. The narratives were produced in fortnightly meetings the students held with accompanied people in their homes and meetings held among supervisors and professors. The content of 120 reports on the completion of the module, produced by the students in 2007 and 2008, was analyzed aiming to identify the effects of the proposed training. Drafting the narratives helped the students expand their listening capacity and their perception of the complexity of the health-disease-care process, in addition to other aspects of what has been called the 'common practice' in the various health professions.
\end{abstract}

Keywords health work; narrative; clinical practice; interprofessional education. 


\section{Introdução}

No campus Baixada Santista da Universidade Federal de São Paulo (Unifesp), em ressonância com movimentos que repensam as lógicas de formação dos profissionais no campo da saúde (Feuerwerker, 2003, 2006), foram implantados a partir de 2006 os cursos de graduação em educação física, fisioterapia, nutrição, psicologia e terapia ocupacional. ${ }^{7}$ As atividades de ensino rompem com a estrutura tradicional centrada em disciplinas e na formação isolada de determinado perfil profissional. Priorizam a formação interprofissional, o trabalho em equipe na perspectiva da integralidade da atenção.

A estrutura curricular dos cursos está organizada em quatro eixos. O eixo 'Aproximação a uma prática específica em saúde' é direcionado aos estudantes de cada área profissional. Os demais eixos ('O ser humano e sua dimensão biológica', 'O ser humano em sua inserção social' e 'Trabalho em saúde') trabalham com turmas que mesclam alunos dos vários cursos.

O eixo trabalho em saúde (TS) percorre os três primeiros anos de graduação e visa possibilitar aos estudantes uma visão abrangente do processo saúde/doença/cuidado e do Sistema Único de Saúde (SUS). Uma estratégia central do eixo consiste em expor os estudantes, desde o primeiro ano da graduação, ao contato com diferentes grupos populacionais e seus problemas de saúde, com movimentos sociais, bem como com as equipes da rede de serviços. Os estudantes são estimulados a assumir responsabilidades crescentes e a realizar intervenções de cuidado de acordo com suas possibilidades. As experiências promovidas pela participação em situações do cotidiano do trabalho em saúde são pontos de partida para a aprendizagem.

A construção das atividades de ensino é orientada pela concepção de que trabalho em saúde opera com um objeto especial, que não é plenamente estruturado. A saúde ganha concretude no modo de viver de cada um e se constitui de forma diferente a depender das marcas sociais, culturais, familiares, das crenças e experiências políticas, do que é ofertado pelos serviços de saúde e de muitos outros elementos. Por mais simples que seja o problema de saúde, ele estará sempre relacionado às condições de vida e a suas múltiplas dimensões: social, biológica, ético-política.

Uma característica fundamental do trabalho em saúde é ser um trabalho 'vivo em ato', que se realiza no momento do encontro entre o trabalhador e quem demanda atenção (Merhy, 2000). Envolve escuta, abertura, espreita, disponibilidade, atenção, certa sensibilidade, tateamento, movimentos de proximidade e distanciamento, implicação, confiança, uma multiplicidade de elementos que não se resume à aplicação de técnicas e protocolos (Deleuze, 2009).

As atividades desenvolvidas no eixo TS pretendem contribuir para formar profissionais com capacidade para lidar com os diversos aspectos que 
envolvem o encontro com quem demanda cuidado, e para estabelecer relações entre as condições de vida e de saúde; a história do sujeito e dos seus adoecimentos; as práticas de saúde e a organização dos serviços, por exemplo. Busca-se ampliar o campo de referências com que cada profissional trabalha, bem como as possibilidades de atuação conjunta das várias áreas profissionais. A perspectiva é da constituição de uma clínica que temos denominado de 'comum' aos profissionais de saúde.

Um dos aspectos desse 'comum' diz respeito ao que seria importante na formação de qualquer profissional da saúde para possibilitar uma atuação que considere as necessidades singulares daqueles que demandam por cuidado. Outra dimensão da clínica comum é a que se realiza no encontro das diferenças das áreas profissionais, e que exige disponibilidade para agenciar e integrar diferentes saberes e práticas, além de se abrir para dimensões que se situam entre os núcleos profissionais e não foram ainda colonizadas pelos marcos disciplinares.

No primeiro ano da graduação, os estudantes realizam atividades de reconhecimento de território que possibilitam perceber os diversos modos de vida da população e suas implicações para o processo saúde-doença-cuidado. Abordam-se ainda as políticas e a organização dos serviços de saúde. A partir do segundo ano, a ênfase está no trabalho com histórias singulares de vida e de saúde.

No terceiro semestre de graduação, no módulo 'Prática clínica integrada: análise de demandas e necessidades de saúde', duplas de estudantes de cursos diferentes acompanham, durante o semestre, uma pessoa ou família. Realizando visitas domiciliares quinzenais, as duplas constroem uma narrativa da história de vida e saúde em conjunto com os acompanhados.

A construção de narrativas de vida tem sido utilizada na prática clínica e na formação de profissionais como estratégia para compreender as relações estabelecidas entre acontecimentos da vida e as questões de saúde, além de acessar os sentidos e significados atribuídos ao adoecimento pelo paciente (Greenhalgh e Hurwitz, 1999; Marcolino e Mizukami, 2008). Ouvir histórias de vida oferece condições para o estudante exercitar a escuta e a sensibilidade diante do sofrimento e desenvolver habilidades para lidar com ele. Também permite perceber questões éticas e políticas envolvidas na clínica.

Do planejamento e da construção dos referenciais que sustentam as atividades desse módulo participam docentes de diferentes áreas de conhecimento dos cinco cursos de graduação. Cada docente é responsável pelo acompanhamento de um grupo de 16 estudantes (oito duplas), de diferentes áreas profissionais, e está vinculado a um serviço. Os trabalhos, com cerca de 240 estudantes por semestre, ocorrem em três diferentes regiões do município de Santos, onde se concentram as áreas de maior vulnerabilidade social (Morro, Centro e Zona Noroeste). 


\section{A articulação do trabalho e a produção de narrativas}

Como ocorre a seleção dos casos e a organização das atividades? Os docentes, em conjunto com a equipe dos serviços, selecionam pessoas e famílias que aceitam receber os estudantes em suas casas e contar suas histórias de vida. Eles visitam as pessoas e famílias selecionadas para apresentar a proposta do módulo (objetivos, horário, duração) e confirmar a sua disponibilidade para os encontros com os estudantes. A contrapartida para os acompanhados é a leitura e a entrega, no final, de uma cópia da narrativa construída. A narrativa, após ser lida, se autorizada pela pessoa acompanhada, é apresentada à equipe do serviço e anexada ao seu prontuário.

Após um período de preparação dos estudantes, no qual são utilizados recursos como textos ${ }^{8}$ e documentários, têm início as atividades de campo. Os estudantes são instigados a perceber, nos encontros, como o sujeito conta sua história de vida: as palavras escolhidas, o modo como se refere a si mesmo e aos grupos/coletivos de que faz parte, as rupturas no fio narrativo que podem expressar sofrimento etc. (Casetto, 2013). Após cada visita, os estudantes elaboram um diário de campo, no qual registram observações, informações, impressões, pensamentos e sensações provocadas pela experiência.

Cada visita é seguida de uma atividade de supervisão em grupo na qual é trabalhado o que emergiu dos encontros: sentimentos mobilizados, angústias, identificações, preconceitos, alegrias, resistências, facilidades, dificuldades e aprendizagens de diversas ordens. Também são problematizados as várias perspectivas acerca das histórias e os caminhos possíveis para a construção da narrativa.

No trabalho realizado em duplas, de diferentes áreas profissionais, emergem diversas perspectivas acerca do que foi ouvido, visto e experimentado. Cabe aos estudantes negociar as distintas visões, buscar consonâncias e ressonâncias e decidir o que será escrito na narrativa. Esse é um exercício inicial de trabalho em comum.

Após a quarta visita domiciliar, a dupla de alunos redige uma primeira versão da narrativa, que é discutida e complementada, se necessário, com outra visita domiciliar, com conversas com profissionais de saúde, consulta de informações em prontuário, entre outros procedimentos. Então é elaborada a narrativa final que será lida para a pessoa acompanhada.

Na narrativa, espera-se que a dupla não faça uma simples justaposição das informações obtidas, mas que as organize para apresentar à pessoa acompanhada e a outro profissional de saúde. Esse trabalho implica escolhas sobre o que dizer, em que sequência e com qual destaque, preservando inclusive a coexistência de sentidos. O conteúdo da narrativa deve incluir: a história de vida e de saúde que se conseguiu obter; a constelação familiar; os recursos atuais com que o sujeito/família conta para sobreviver; as razões 
que ele apresenta para sua doença ou situação; as estratégias utilizadas para manter a saúde; os atendimentos e tratamentos que vem realizando. Busca-se, no texto, apontar para as necessidades de saúde do acompanhado, estabelecendo relações com sua história de vida e sua condição social.

Além da narrativa elaborada pela dupla, os estudantes entregam, no final do módulo, um relatório individual em que descrevem e discutem a experiência. Para este texto, analisamos relatórios dos anos de 2007 e 2008.

Esse material ${ }^{9}$ integra as investigações que vêm sendo realizadas pelo Laboratório de Pesquisa e Estudos sobre Formação e Trabalho em Saúde (Lepets), mais especificamente a pesquisa "Formação para o trabalho em saúde: a experiência em implantação nos cursos de educação física, fisioterapia, nutrição, psicologia, terapia ocupacional da Universidade Federal de São Paulo, Campus Baixada Santista", aprovada pelo Comitê de Ética sob o número 1528-09.

Foram selecionados $30 \%$ dos relatórios produzidos em cada ano, mantendo a proporção entre as diferentes regiões da cidade onde ocorre módulo. No total, procedeu-se à análise de conteúdo de 120 relatórios.

Para a análise, foram realizadas leituras visando a uma apreensão da diversidade de temas abordados e da singularidade de cada material. Elaborou-se um quadro com os temas identificados, com as diferentes posições expressas pelos participantes a respeito desses temas, os trechos de discursos mais significativos que exemplificavam essas posições, bem como as impressões e as questões que o material suscitava durante a leitura (Bardin, 2000).

Em seguida, procedeu-se à leitura do conjunto do material procurando comparar tendências, predominâncias, diferenças e singularidades. Para este relato, foram selecionados alguns trechos que indicavam aprendizagens, tensões e efeitos possíveis dessa proposta de formação, que apresentamos e comentamos a seguir.

\section{Exercícios para uma clínica comum: estranhamentos, encontros, complexidade}

O início dos contatos é um desafio. Embora as regiões tenham sido visitadas no primeiro ano, voltar a elas com a tarefa de ouvir os sujeitos nas suas próprias casas tende a suscitar muitas dúvidas e medo.

Como se deve entrar no cotidiano de uma pessoa? Estar presente, nem que seja um dia da semana, na casa de uma pessoa desconhecida? Quais sensações, sentimentos e ações isso pode provocar? Tais questões surgiram devido a um certo receio que eu tinha de estar em um ambiente totalmente estranho, o fato de não saber o que iria encontrar, se seria aceito e se isso realmente serviria para acrescentar alguma experiência para minha vida profissional como educador físico (Educação física, 2007, Centro). 
A preparação para o campo ocupou várias semanas de aula, incluindo discussões nas quais todos os estudantes foram convidados a expor suas questões e temores. Apesar da preparação, certo estranhamento inicial foi inevitável; diante dele, surgia a tendência de utilizar preconcepções, capazes de resolver o incômodo, tornando-o classificável e reconhecido:

Com este trabalho, as maiores dificuldades talvez tenham sido os momentos de silêncio, mas acima de tudo de lidar com o diferente, sem partir de ideias prefixadas como se tentássemos colocar as pessoas em padrões prefixados (Psicologia, 2008, Zona Noroeste).

Por vezes tratava-se de abandonar juízos de valor, ou ao menos não deixá-los impedir a continuidade da experiência:

A casa encontrava-se na região das palafitas, e foi naquele dia que entendi a verdadeira realidade que viviam todas aquelas pessoas. Nas primeiras visitas fiquei muitíssimo incomodada, mas à medida que aconteciam as visitas, esse desconforto pôde ser minimizado. No começo era muito difícil conversar e me atentar somente à escuta, meu pensamento voava, tentava imaginar como conseguiam morar naquele lugar, tentava não mostrar meu desagrado perante o odor que sentia, tentava agir normalmente diante dos fatos que mais mexiam comigo (...) naqueles momentos tive que deixar meus julgamentos de lado, minhas suposições e hipóteses baseadas em minha vivência pessoal (Terapia ocupacional, 2008, Zona Noroeste).

Perceber as preconcepções é doloroso, mas é também importante e um bom antídoto contra o 'já sabido', que nos distancia dos encontros; permite suportar um pouco mais o não saber: "Acompanhamos apenas um caso e tentamos 'juntar as peças', mas muitas lacunas e mistérios ficaram ocultados" (Nutrição, 2008, Zona Noroeste). Com a largueza de não saber tudo, podia-se também valorizar o ponto de vista do colega e aprender com ele:

Percebemos que muitas vezes atentávamos a fatos diferentes e que a junção dos nossos olhares compunha um quadro mais completo (...) muitas vezes eu entendia algo de forma diferente da minha dupla (...) isso fez-me ver outras possibilidades e não afirmar verdades absolutas; passei a considerar mais hipóteses (Terapia ocupacional, 2008, Zona Noroeste).

Muitas situações eram imprevistas, de modo que não se tratava de saber antes o que fazer, mas aprender a decidir como agir frente aos acontecimentos: 
Entendi que lidar com as situações só é aprendido no ato de vivenciá-las, pois não temos a capacidade de prever todos os fatos e muito menos imaginar uma reação precisa a cada um deles (Terapia ocupacional, 2008, Zona Noroeste).

Por meio das visitas, era possível conhecer alguns dos obstáculos enfrentados cotidianamente pelos moradores:

Foi difícil subir aquela rua com uma subida demasiadamente acentuada (...) fiquei me questionando a dificuldade dos idosos, das pessoas com problemas de coluna, da perna ou algum problema de saúde (...) subíamos um pedaço e parávamos para respirar e subir novamente (...) não bastando a inclinação da rua, ela era estreita e não possuía calçada (Nutrição, 2008, Morro).

Foi possível perceber que a confiança deveria ser construída, não se dando de forma imediata; e, mais importante, que é com essa implicação que se poderia acessar as histórias de vida:

Fui aos poucos percebendo que se eu não ganhasse a confiança dela, ela nunca se sentiria à vontade para contar sua história, e sem conhecer sua história eu não poderia compreender suas dificuldades (Fisioterapia, 2007, Centro).

Não se tratava de afirmar a relação teórica entre saúde-doença-cuidado, condições de vida e serviços de saúde, mas de perceber, por meio de uma história concreta, o imbricamento desses fatores. Nos encontros, as complexidades puderam ser vislumbradas: “(...) quando cheguei ao sujeito, percebi com muita clareza que ali havia um mundo complexo onde certamente iríamos percorrer minimamente uma superfície" (Psicologia, 2008, Morro). Saúde e doença não poderiam ser reduzidas aos aspectos biológicos: "fiquei satisfeita (...), pois conseguimos (...) comprovar que o adoecimento ultrapassa a barreira do biológico" (Nutrição, 2008, Morro).

Era importante perceber que havia quem não entendesse o que estava acontecendo consigo: “o médico não deixou claro o que ela tinha. Ela não sabia explicar o que tinha e os exames que tinha que fazer" (Fisioterapia, 2007, Zona Noroeste). Conhecer o ponto de vista do acompanhado significava encontrar outros sentidos atribuídos aos sintomas e outras etiologias supostas para eles: “aprendi que é preciso lembrar a todo instante que há várias interpretações para a mesma doença" (Nutrição, 2007, Zona Noroeste).

Não se tratava de negar a importância do conhecimento técnico, mas de perceber que ele devia combinar-se com o conjunto dos demais aspectos que compõem o cuidado em saúde: “(...) absorvi que o conhecimento técnico isolado tem pouca repercussão no atendimento (...) precisa-se criar vínculo e ter uma boa comunicação para o diagnóstico e tratamento serem eficazes" 
(Fisioterapia, 2008, Morro). Senão, corre-se o risco de fazer orientações e prescrições terapêuticas impraticáveis: “(...) seu médico recomendou que ela caminhasse todos os dias meia hora, mas M. morava no morro e era bastante complicado andar para comprar mantimentos, imagine para se exercitar" (Nutrição, 2008, Morro).

Com essa visão ampliada sobre o paciente, sua história e sua vida, os diagnósticos já estabelecidos, por vezes, mostravam pouca precisão:

Apesar de ter sido diagnosticada com depressão, durante nossas visitas não foi o que percebemos (...) no caso de M. a paraplegia e seu contexto de vulnerabilidade econômica foram certamente utilizados para fazer o diagnóstico de depressão (...) todavia constatamos que se trata de uma senhora que a vida exigiu muito e parece ter sido fortalecida nisso (Psicologia, 2008, Morro).

A afirmação da importância desses aspectos, se tratados somente em sala de aula, seria facilmente aceitável, mas a experiência dos encontros dava-lhes uma força incomparável de convencimento:

Desde o início do módulo foi ressaltada a importância de ter capacidade de escutar, observar e entender o paciente. Muitos textos enfatizavam o valor que têm o vínculo e a confiança em uma relação terapêutica. No entanto, só pude 'sentir' o quanto estabelecer esse contato é importante para um profissional de saúde e para o desenvolvimento de seu trabalho após conhecer V. e conquistar um pouco da sua confiança (Fisioterapia, 2007, Centro).

Várias referências foram feitas acerca da potência dos encontros:

Foram experiências únicas em minha vida, me senti estimulada com tudo (...) ao longo das visitas me sentia como num labirinto procurando uma saída para ajudar I. (...) depois pude perceber que nossa conversa não era em vão e que I. refletia sobre o que falávamos (Nutrição, 2008, Zona Noroeste).

Encontramos ainda menções a capacidades desenvolvidas, como a de lidar com situações incômodas:

A atividade do módulo ressignificou minha ideia de atendimento clínico, pois o que imaginava foi bem diferente do que vivenciei na prática do trabalho em saúde (...) hoje entendo que um dos motivos da eficácia de um projeto de intervenção advém de um grande processo de escuta do profissional (...) escuta essa permeada por momentos confortáveis e desconfortáveis (...) o saber lidar com os momentos desconfortáveis foi algo que conquistei neste pequeno processo de visitas (Terapia ocupacional, 2008, Zona Noroeste). 
Mas também se pôde aprender com os acompanhamentos que não conseguiram se completar:

Este semestre foi repleto de informações teóricas e práticas (...) passamos por diversas experiências que, para mim, apesar de não ter sido a melhor e nem a que eu esperava, contribuiu para aprender que as pessoas não são como nós queremos (...) eu tive um grande amadurecimento (Terapia ocupacional, 2008, Morro).

A escrita da narrativa, ela própria, apresentava o desafio de reunir informações relevantes e apresentar a história da pessoa, mas sem revelar o que pudesse prejudicá-la de algum modo. Tal questão ética pôde ser percebida por mostrar-se no contexto de uma relação de confiança:

É um processo complexo escrever sobre a vida de uma pessoa que conhecemos em tão pouco tempo, sem expor, tomando os devidos cuidados, mas também, ao mesmo tempo, colocando fatos importantes, suavizando alguns detalhes, omitindo outros, pois assim que nos foi pedido: escrever algo sem quebrar o laço de confiança que construímos (Nutrição, 2008, Morro).

Mas a montagem da história, a concatenação dos fatos e acontecimentos de saúde, ajudou também no estabelecimento dos nexos, dos quais se alimenta o raciocínio clínico:

Como o objetivo era escrever dados relevantes sobre o personagem para informar outro profissional de saúde, buscamos falar das dificuldades que a senhora passou ao longo de sua vida, o sofrimento, a mudança em seu dia a dia após a doença, o que isso significou para ela e como vive atualmente (...) construir a narrativa foi algo muito bom de fazer (...) trabalhou o nosso raciocínio clínico (Terapia ocupacional, 2008, Morro).

\section{Efeitos relatados}

A avaliação da experiência pelos alunos fez destacar alguns de seus efeitos na própria formação. Um deles diz respeito à necessidade de não tomar apenas a demanda imediata como parâmetro para ação:

Com certeza, durante minha prática profissional, independente da pessoa que estiver atendendo, lembrarei dessa vivência e poderei fazer um bom atendimento e obter um melhor resultado, considerando a pessoa atendida dentro de um contexto de vida e analisando não somente a demanda imediata, mas suas necessidades de saúde (Nutrição, 2007, Centro). 
Houve também a impressão de que o campo sensível foi ampliado:

Foi essencial fazer esse trabalho em saúde, tanto pela nossa sensibilidade, que se alargou mais, quanto a de M., que já nos chamou para visitá-la em outras ocasiões (...) saber como mergulhar na história de vida do outro é um exercício para a vida toda que aqui só começamos (Psicologia, 2008, Morro).

Um efeito mútuo de transformação pelo trabalho realizado também foi percebido:

Em toda esta experiência a sensação é de transformação. Transformação de minha subjetividade, da de M. também. Essa vivência convergiu para um vínculo terapêutico único em que entrevistado e entrevistador são afetados (Psicologia, 2007, Zona Noroeste).

Mas talvez as mais fortes impressões tenham vindo das reações à leitura das narrativas:

Perguntamos se ela gostaria de ficar com uma cópia da narrativa. Ela disse que sim, afirmando que aquilo não tinha preço, pois era a história da vida deles (...) ela pedirá para alguém ler para o seu marido (Nutrição, 2008, Morro).

Eu observava atentamente as reações de D. ao escutar a sua história. Foi impressionante sua reação; aquela expressão rude que havia nos demonstrado estava escondida atrás de um olhar cheio de lágrimas que escorriam no final da leitura (...) ela me abraçou de uma maneira tão intensa que eu me emocionei, não conseguia entender o que estava sentindo (Fisioterapia, 2008, Zona Noroeste).

Por vezes, o espelho da narrativa fazia com que a pessoa descobrisse outra imagem de si:

Ao final da leitura ela disse que não era tudo aquilo, que tínhamos mostrado uma pessoa M. mais do que realmente era; talvez nesse momento ela tenha se dado conta de quão importante é, de tudo que fez e do quanto batalhou (Nutrição, 2008, Morro).

O momento da leitura mostrou ser importante para dar sentido ao módulo, às vezes questionado pelos alunos em seu decorrer, desconfiados da eficácia da elaboração da narrativa. Nesse momento final, é impactante perceber que a imaterialidade dos encontros e a materialidade da narrativa construída produzem efeitos na pessoa acompanhada e nos estudantes. É como se boa parte do significado desse processo ficasse clara somente ao seu término, retrospectivamente. 
Finalmente, é instigante perceber a relação feita da condição pré-especialização em que os estudantes se encontram no segundo ano e a abertura à alteridade e complexidade que tal condição permite. Trata-se de uma boa compreensão do que temos chamado de 'clínica comum':

Percebi que, apesar da pouca formação específica de psicologia que obtive até agora, foi completamente possível ir a campo e obter uma resposta positiva. Essa 'pouca formação' pode ser inclusive enriquecedora, já que nos permite ver os problemas não com um olhar de psicólogo, mas como um olhar de futuro psicólogo, atuando ao lado de futuros educadores físicos, futuros nutricionistas etc. Esse trabalho pré-especialização é enriquecedor justamente por não nos deixar limitados unicamente à nossa área de atuação, mas sim abertos à complexidade (Psicologia, 2007, Centro).

\section{Considerações finais}

Os relatórios escritos, em que pese o fato de se tratar de um trabalho de conclusão de semestre que integra parte da avaliação dos estudantes, expressaram as problemáticas e o que há de mais fecundo nessa proposta. As questões que emergiram ressoam com os relatos dos envolvidos nesse processo de formação, ao longo dos últimos anos, e também com as investigações que vêm sendo realizadas pelo Laboratório de Estudos e Pesquisas em Formação e Trabalho em Saúde (Lepets) do campus Baixada Santista. 10

Pode-se dizer que a construção de narrativas tem se revelado uma estratégia potente para o exercício da alteridade, da escuta sensível, da capacidade de sustentar o encontro clínico. Também para perceber 'pré-conceitos' e aprender a lidar com o inesperado. Permite acessar uma multiplicidade de modos de viver e manter a saúde, bem como possibilita perceber limites das práticas profissionais protocolares.

Utilizar o recurso das narrativas na formação de profissionais de saúde nos ensina que os sentidos compartilhados são mais potentes, e que a elaboração conjunta destes últimos tem uma eficácia maior que a da prescrição técnica unilateral. E sobretudo que qualquer intervenção em saúde ocorre num âmbito complexo que envolve sujeitos. Condições favoráveis a ela nem sempre são dadas de antemão, amiúde tendo que ser construídas. Mas esse não é um processo sem riscos de lado a lado, sendo o maior deles a possibilidade de se sair transformado ao final. Trata-se de exercícios para uma clínica comum. 


\section{Colaboradores}

Todos os autores participaram de todas as etapas da elaboração do artigo.

Resumen En este trabajo se presenta la experiencia de formación común que ocurre desde 2007 en el campus Baixada Santista de la Universidad Federal de São Paulo (Sureste de Brasil), en el tercer semestre de pregrado, del eje curricular trabajo en salud. La experiencia articula estudiantes y docentes de diferentes áreas profesionales: educación física, fisioterapia, nutrición, psicología y terapia ocupacional. Se presentan las directrices y estrategias de organización del módulo "Práctica clínica integrada: análisis de demandas y necesidades de salud", que adopta la producción de narrativas de historias de vida y de temas de salud de personas seleccionadas por docentes conjuntamente con los equipos de la red de servicios del municipio de Santos, São Paulo. Las narraciones fueron producidas en reuniones quincenales de los estudiantes con las personas seguidas, en sus residencias, y de supervisiones con los docentes. Se realizó un análisis de contenido de 120 informes de conclusión del módulo preparados por los estudiantes en los años 2007 y 2008 buscando identificar los efectos de esta propuesta de formación. La preparación de narrativas propició que los estudiantes ampliaran su capacidad de escuchar y su percepción de la complejidad del proceso salud-enfermedad-cuidado, así como de otros aspectos de lo que se ha denominado "clínica común" a las diversas profesiones en salud.

Palabras clave trabajo en salud; narrativa; práctica clínica; formación interprofesional.

\section{Notas}

1 Universidade Federal de São Paulo, Santos, São Paulo, Brasil.

Doutora em Saúde Coletiva pela Universidade Estadual de Campinas.

<angeruma@uol.com.br>

Correspondência: Rua Bittencourt Sampaio, 210, Vila Mariana, CEP 04126-060, São

Paulo, SP, Brasil.

2 Universidade Federal de São Paulo, Santos, São Paulo, Brasil.

Doutor em Psicologia Clínica pela Pontifícia Universidade Católica de São Paulo.

<sidneicazeto@uol.com.br>

3 Universidade Federal de São Paulo, Santos, São Paulo, Brasil.

Doutora em Educação pela Pontifícia Universidade Católica de São Paulo.

$<$ jaque_ibrizi@yahoo.com.br>

4 Universidade Federal de São Paulo, Santos, São Paulo, Brasil.

Doutor em Psicologia Clínica pela Pontifícia Universidade Católica de São Paulo.

$<$ alexandrehenz2000@yahoo.com.br> 
5 Universidade Federal de São Paulo, Santos, São Paulo, Brasil.

Doutor em Saúde Coletiva pela Universidade Estadual de Campinas.

$<$ tykanori@hotmail.com>

6 Universidade Federal de São Paulo, Santos, São Paulo, Brasil.

Doutora em Saúde Pública pela Universidade de São Paulo. <fatiquei@outlook.com>

7 A partir de 2009 teve início a implantação do curso de serviço social, com uma turma no período da tarde e outra no período noturno. A experiência que relatamos aqui ocorreu apenas com os cinco cursos inicialmente implantados no campus Baixada Santista.

8 Os textos preparatórios para as atividades de campo incluem orientações e materiais elaborados pelos docentes do eixo.

9 Este texto é uma versão modificada do artigo "Clínica comum dos profissionais de saúde: relato da experiência de formação em implantação no eixo do trabalho em saúde Unifesp - Campus Baixada Santista", que foi premiado na temática de experiências inovadoras na formação no Congresso da Rede Unida de 2009 - IV Prêmio Mario Chaves.

10 Atualmente, a pesquisa sobre formação para o trabalho em saúde "A experiência em implantação nos cursos de graduação da Universidade Federal de São Paulo - Campus Baixada Santista", financiada pelo Conselho Nacional de Desenvolvimento Científico e Tecnológico (CNPq), processo n. 479031-8, está concluída. Seus resultados estão organizados no livro Clínica comum: itinerários de uma formação em saúde, que teve como organizadores Angela A. Capozzolo, Sidnei J. Casetto e Alexandre de O. Henz, publicado pela Hucitec (São Paulo) em 2013.

\section{Referências}

BARDIN, Laurence. Análise de conteúdo. Lisboa: Edições 70, 2000.

CASETTO, Sidnei J. A narrativa na clínica comum. In: CAPOZZOLO, Angela A.; CASETTO, Sidnei J; HENZ, Alexandre de O. (Orgs.). Clínica comum: itinerários de uma formação em saúde. São Paulo: Hucitec, 2013.

DELEUZE, Gilles. Cursos sobre Spinoza: Vincennes, 1978-1981. Tradução de Emanuel Angelo da Rocha Fragoso et al. Fortaleza: EdUECE, 2009.
FEUERWERKER, Laura C. M. Educação dos profissionais de saúde hoje: problemas, desafios, perspectivas e as propostas do Ministério da Saúde. Revista Abeno, São Paulo, v. 3, n. 1, p. 24-27, 2003.

Estratégias para a mudança na graduação das profissões da saúde. Cadernos da Abem, Rio de Janeiro, v. 2, p. 78-80, 2006.

GREENHALGH, Trisha; HURWITZ, Brian. Narrative based medicine: why study narrative?. British Medical Journal, Inglaterra, 
v. 318, n. 2, 1999. Disponível em: <www. bmj.com/content $/ 318 / 7175 / 48$. 1 .full?sid= 28222b0f-5b35-4a5d-8004-47eblafc3275>. Acesso em: 8 set. 2011.

MARCOLINO, Taís Q.; MIZUKAMI, Maria G. N. Narrativas, processos reflexivos e prática profissional: apontamentos para pesquisa e formação. Interface: Comunicação, Saúde, Educação, Botucatu, v. 12, p. 541547, 2008.
MERHY, Emerson E. Um ensaio sobre o médico e suas valises tecnológicas. Interface: Comunicação, Saúde, Educação, Botucatu, v. 6, n. 6 , p. 109-125, 2000.

Recebido em 28/09/2011

Aprovado em 27/08/2013 